\title{
p53 codon 72 polymorphisms and random amplified polymorphic DNA analysis of non-melanoma skin cancer through archival formalin-fixed paraffin-embedded tissue
}

\author{
CHEAH YOKE-KQUEEN ${ }^{1,3}$, NURUL-SYAKIMA AB MUTALIB ${ }^{1}$, \\ SHIRAN MOHD SIDIK ${ }^{2}$, LEE LEARN-HAN ${ }^{1}$ and TAN GEOK-CHIN ${ }^{4}$
}

\begin{abstract}
Departments of ${ }^{1}$ Biomedical Science, and ${ }^{2}$ Pathology, Faculty of Medicine and Health Sciences, ${ }^{3}$ Diagnostic Imaging Nuclear Centre, Universiti Putra Malaysia, 43400 UPM Serdang, Selangor Darul Ehsan; ${ }^{4}$ Department of Pathology, Universiti Kebangsaan Malaysia Hospital, Jalan Ya'acob Latif, Bandar Tun Razak, 56000 Cheras, Kuala Lumpur, Malaysia
\end{abstract}

Received August 3, 2011; Accepted September 29, 2011

DOI: 10.3892/or.2011.1581

\begin{abstract}
Non-melanoma skin cancer (NMSC) is classified among the ten most frequent cancers in Malaysia. A common polymorphism at codon 72 of the p53 tumor suppressor gene and its influence on cancer risk has been studied for different types of cancer with mixed and inconsistent results with limited published data on the Malaysian population so far. In the present study, the frequency of p53 codon 72 polymorphism in 60 patients with NMSC was investigated from archival formalin-fixed paraffin-embedded (FFPE) tissue obtained from Hospital Universiti Kebangsaan Malaysia (HUKM). Additionally, random amplified polymorhic DNA -polymorphic chain reaction (RAPD-PCR) was employed for preliminary biomarker development. NMSC FFPE samples (70\%) possess $\mathrm{Arg} / \mathrm{Arg}, 20 \%$ with Pro/Pro and $10 \%$ with $\mathrm{Arg} /$ Pro. In total, there was no significant difference in the p53 codon 72 genotypes between histological types of NMSC, gender, race, tumor location and age group. However, there was an apparent age-associated increase in the $\mathrm{Arg} / \mathrm{Arg}$ genotype but did not reach statistical significance $(\mathrm{P}=0.235)$. NMSC types and demographic characteristics did not influence genotype distribution. On the other hand, BCC and SCC distributions are influenced by age group, race and tumor location.
\end{abstract}

\section{Introduction}

Non-melanoma skin cancer (NMSC) is the most common type of cancer among different populations worldwide.

Correspondence to: Dr Cheah Yoke-Kqueen, Department of Biomedical Science, Faculty of Medicine and Health Sciences, Universiti Putra Malaysia, 43400 UPM Serdang, Selangor Darul Ehsan, Malaysia

E-mail: ykcheah@medic.upm.edu.my

Key words: non-melanoma skin cancer, p53 codon 72 polymorphism, FFPE tissue, demographic characteristics, RAPD-PCR
Consisting of two histological types i.e. basal cell carcinoma (BCC) and squamous cell carcinoma (SCC), the BCC accounts for $80 \%$ and SCC for the rest (1). Regardless of its low clinical aggressiveness, due to its frequency and cost of treatment, it is a heavy public health burden (2). In Malaysia, official statistics rank NMSC among the ten most common types of cancer in adults (3). Exposure to sun is considered the main causative agent for NMSC (4). However, it cannot account for all of NMSC etiology since other physical and chemical agents, such as ionizing radiation, arsenic and coal tar products, as well as suppression of immune system in transplant patients, are verified causes of NMSC (5). Furthermore, genetic polymorphism is proposed to modify the risk of the disease (6).

The $\mathrm{p} 53$ tumor suppressor protein plays an essential part in maintaining cellular integrity and tissue homeostasis through its ability to orchestrate the transcriptional activation of other genes (7). A critical region of p53 for signaling apoptosis lies between codons 64 and 92, encoding a proline-rich region of the gene homologous to an SH3 binding domain (8-10) in which there is a common polymorphism resulting in either an arginine (CGC) or a proline (CCC) at codon 72 of exon 4. This is a non-conservative amino acid change and results in a structural change in the protein as the p53Pro variant migrates more slowly than the p53Arg variant in sodium dodecyl sulfatepolyacrylamide gel electrophoresis (11). The two alleles of p53 differ biologically. p53Arg induces 5-10 times more apoptosis than p53Pro, which is explained in part by a higher ability of p53Arg to localize to the mitochondria (12).

Lung cancer patients with the Pro/Pro genotype, especially those who were smokers, were more likely to develop lung cancer than those with other genotypes $(13,14)$. On the contrary, non-smokers with lung cancer have an increased frequency of the homozygous Arg genotype (15).

Increased frequency of the Pro allele (Pro/Pro or Arg/Pro genotypes) was also found in patients with breast cancer (16). Controversial finding is reported on the association between the polymorphism and cervical cancer (17), but in vitro study suggested that the Arg form of p53 was more susceptible to the E6 oncoprotein (derived from tumor-associated human 
papillomaviruses)-mediated degradation than was the Pro form (18).

McGregor et al (19) found that in high-risk immunosuppressed groups, p53Arg was associated with the development of both basal and squamous cell carcinomas, but this relationship was not demonstrable in immunocompetent patients with NMSC.

The influence of p53 codon 72 polymorphism on cancer risk has been studied for different types of cancer with mixed, controversial and inconsistent results. There are few studies with small sample sizes and most of the studies have found no association between p53 genotype at codon 72 and NMSC. Different population showed different distribution of the genotypes thus leading to different association with cancer susceptibility. Essentially, the genetic background of Malaysian population is distinct from the population being studied. Therefore, we cannot conclude the association between this polymorphism with NMSC from studies conducted in other populations.

With the establishment of the data on the relationship between p53 codon 72 polymorphism and NMSC, further association studies of other cutaneous disease involving this polymorphism can be done. Therefore, further genotyping of Malaysian with NMSC can actually predict the risk of getting NMSC or other related cutaneous disease.

On the other hand, various studies have applied RAPD-PCR for the analysis of genetic alterations in human tumors and revealed frequent occurrence of genetic polymorphisms in various types of tumors, for instance, lung cancer (20), squamous cell carcinoma of the head and neck (21), brain tumor (22), ovarian cancer (23), breast cancer $(24,25)$, hepatocellular carcinoma $(26,27)$, lymphoma (28) and in leukemia (29).

\section{Materials and methods}

Study subjects. Formalin-fixed, paraffin-embedded skin tissue samples were obtained with ethical permission from the archival tissue banks in the Departments of Pathology at Hospital University Kebangsaan Malaysia (HUKM), Malaysia from January 2003 to December 2006. A total of 89 specimens diagnosed with NMSC. This study was approved by the research ethics committees of Faculty of Medicine and Health Sciences, University Putra Malaysia with the reference number [UPM/FPSK/PADS/T7MJKEtikaPer/f01(JSB_FEB (08) 47] and approved permission from the head of Pathology Department, Hospital University Kebangsaan Malaysia dated 3rd October 2007.

Histological processing of FFPE tissue. All the FFPE tissue were sectioned using a microtome to obtain sections of $5 \mu \mathrm{m}$ in thickness, placed on $40 \mathrm{~mm}$ frosted-end glass slides in the Histopathology Laboratory, Faculty of Medicine and Health Sciences, University Putra Malaysia. H\&E staining was performed on these sections and subsequently were subjected to confirmation by pathologist.

Genomic DNA extraction. The genomic DNA from FFPE tissue was extracted according to protocols reported by Greer et al (30) with several modifications. A reagent used on the tissue sections in this study includes; $10 \%$ bleach solution (freshly diluted), xylene, $100 \%$ ethanol, acetone, proteinase $\mathrm{K}$ (20 mg/ml stock solution), phenol, chloroform and digestion buffer: $50 \mathrm{mM}$ Tris-HC1 (pH 8.5); $1 \mathrm{mM}$ EDTA; and 0.5\% Tween-20. Briefly, replicate sections (10-20 $\mu \mathrm{m})$ are cut from each block, and a single section placed in a sterile, $1.5-\mathrm{ml}$ microcentrifuge tube. Sections of the tumor were then treated with xylene, ethanol, proteinase $\mathrm{K}$, phenol and chloroform.

Genotyping of p53 codon 72 . p53 codon 72 polymorphism detection was carried out by an allele specific PCR described by Pezeshki et al (31) with slight modification on a Palm Cycler (Corbett Research, Australia). To detect the p53 codon 72 polymorphism, two primer sets in separate tubes were used, one to amplify the Arg allele and the other to amplify the Pro allele as follows: Arg forward, TCC CCC TTg CCg TCC CAA, Arg reverse, CTg gTg Cag ggg CCA CgC; Pro forward, gCC AgA ggC TgC TCC CCC, Pro reverse, CgT gCA AgT CAC AgA CTT. Each set of primers with concentration of 10 pmol were used in a different tube in a total volume of $20 \mu \mathrm{l}$ containing $2 \mu \mathrm{l}$ DNA template, $2 \mu \mathrm{l}$ of $10 \mathrm{mM}$ dNTPs (2.5 mM each), $0.2 \mu \mathrm{l}$ (5 U/ $\mu 1$ ) i-Taq ${ }^{\mathrm{TM}}$ Plus DNA Polymerase, $2 \mu 1$ 10x i-Taq ${ }^{\mathrm{TM}}$ Plus PCR buffer [350 mM Tris-HCl (pH 9.0), $250 \mathrm{mM} \mathrm{KCl,} 35 \mathrm{mM}$ $\mathrm{MgCl}_{2}$ and enhancer solution] and 11.8- $\mu \mathrm{l}$ ultrapure sterile distilled water. Reagents for PCR master mix were purchased from iNtRON Biotechnology, Korea. The amplification was performed for 35 cycles under a touchdown program; by denaturation at $94^{\circ} \mathrm{C}$ for $30 \mathrm{sec}$, annealing at $68-62^{\circ} \mathrm{C}$ for 10 cycles and $62-58^{\circ} \mathrm{C}$ for 25 cycles, and extension at $72^{\circ} \mathrm{C}$ for $30 \mathrm{~min}$ in each cycle using personal Palm Cycler (Corbett Research). The amplicons were resolved by electrophoresis in $2.5 \%$ agarose (Promega, USA) with $50 \mathrm{~V}$ for $45 \mathrm{~min}$ in $1 \mathrm{X}$ TBE buffer. The gel was then stained with ethidium bromide and visualized using Alpha Imager System (Alpha Innotech, USA) with 100 bp DNA ladder (New England Biolabs, USA) as the standard DNA molecular weight marker. The PCR product of the Arg allele yielded $141 \mathrm{bp}$, while Pro allele yielded $177 \mathrm{bp}$. Selected products were subjected for sequencing. The negative control was included i.e. complete PCR reaction mixture without template DNA, to exclude the possibility of crosscontamination during sample preparation. The genotypes of $<10 \%$ samples were reassessed to confirm the results.

Random amplified polymorphic DNA-PCR. Three arbitrary primers of 10 mers length were selected after primer screening which were the OPO-09, OPO-12 and OPO-20 (Operon, Germany). Selection was based upon which primers gave the best banding profiles. The RAPD was performed in a $20 \mu 1$ volume containing $2 \mu \mathrm{l} 10 \mathrm{X}$ i-Taq ${ }^{\mathrm{TM}}$ Plus PCR buffer $[350 \mathrm{mM}$ Tris- $\mathrm{HCl}$ (pH 9.0), $250 \mathrm{mM} \mathrm{KCl,} 35 \mathrm{mM} \mathrm{MgCl}_{2}$ and enhancer solution], $1.0 \mu \mathrm{l}$ of primer (OPO-09, OPO-12 and OPO-20), $2.0 \mu \mathrm{l}$ of $10 \mathrm{mM}$ dNTPs (2.5 mM each), $0.2 \mu \mathrm{l}(5 \mathrm{U} / \mu \mathrm{l}) \mathrm{i}-\mathrm{Taq}^{\mathrm{TM}}$ Plus DNA Polymerase, $13.8 \mu \mathrm{l}$ ultrapure sterile distilled water and $1 \mu \mathrm{l}$ of $46 \mathrm{ng}$ DNA template. Reagents for PCR master mix were also purchased from iNtRON Biotechnology, Korea. Amplification was performed in a Thermal Cycler (Eppendorf, Germany) with a temperature program consisting of initial denaturation at $94^{\circ} \mathrm{C}$ for 3 min followed by 30 cycles of denaturation at $94^{\circ} \mathrm{C}$ for $1 \mathrm{~min}$, annealing at $36^{\circ} \mathrm{C}$ for $1 \mathrm{~min}$ and polymerization at $72^{\circ} \mathrm{C}$ for $2 \mathrm{~min}$. Final elongation was performed at $72^{\circ} \mathrm{C}$ for $7 \mathrm{~min}$. The amplicons were then 

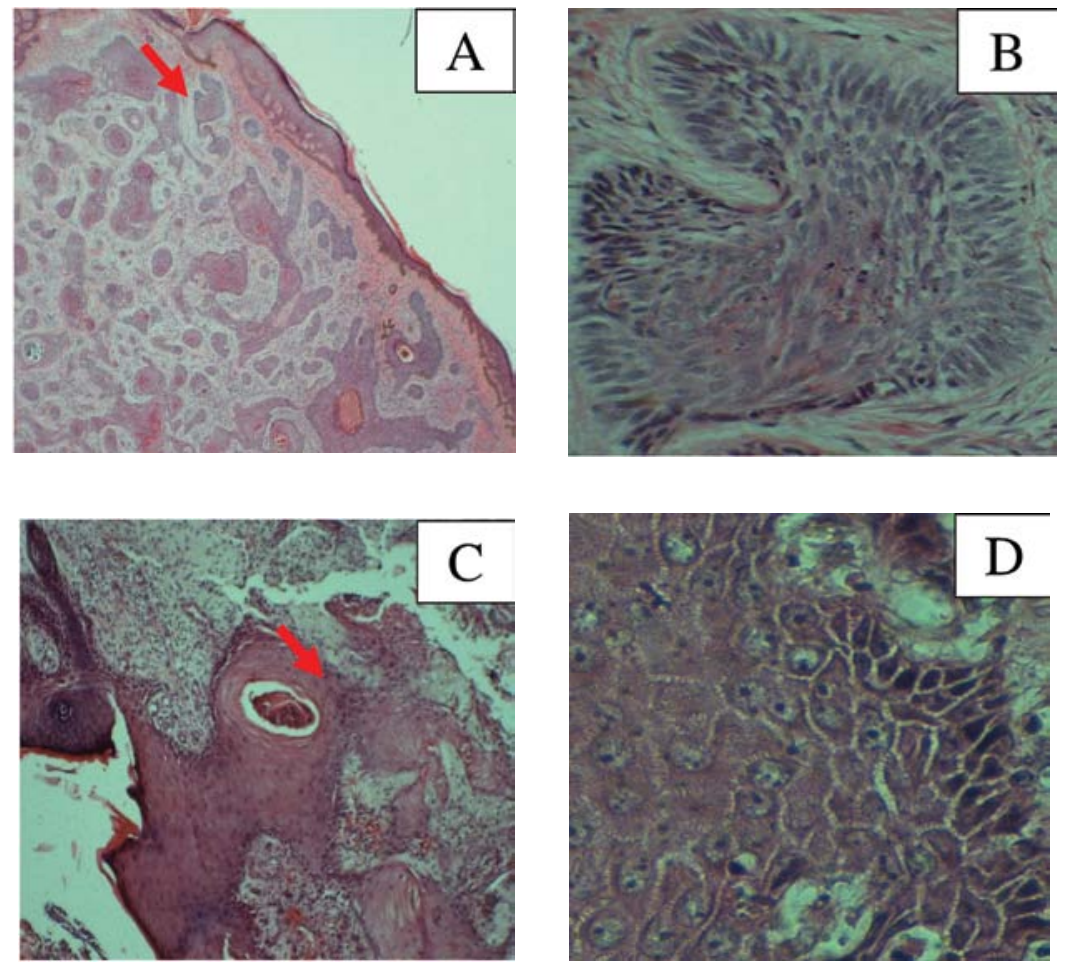

Figure 1. Representative histological pictures of NMSC of skin. Red arrows indicate tumor cells and area that were magnified. (A) Basaloid nests within dermis (magnification, $\mathrm{x} 4$ ). (B) Palisading of peripheral cells and separation from adjacent stroma by thin cleft (magnification, $\mathrm{x} 4$ ). (C) Atypia throughout epidermis with extension into dermis and presence of keratin pearl (magnification, $x 10)$. (D) Intercellular bridges ( magnification, $\mathrm{x} 40$ ).

resolved in $1.8 \%$ agarose (Promega, USA) Gel Electrophoresis with $100 \mathrm{~V}$ for $\sim 2 \mathrm{~h}$ in $1 \mathrm{X}$ TBE buffer. The gel was then stained with ethidium bromide and visualized using Alpha Imager System (Alpha Innotech, USA). The 1-kb DNA ladder (New England Biolabs) was used as the standard DNA molecular weight marker. Generated banding profiles were subjected to RAPDistance software to generate dendrogram for clustering analysis with Jaccard and Dice coefficient.

Statistical analysis. Association between p53 codon 72 genotypes and NMSC was assessed by the $\chi^{2}$ test and Fisher's exact test (when the expected number in any cell was $<5$ ). The basic significance level was fixed at $\mathrm{P}<0.05$. $\mathrm{P}$-value $<0.05$ was considered as significantly different. The statistical analysis was performed using the statistical package SPSS 14.0 for Windows software. In addition, associations between the characteristics of the subjects were also assessed using the same statistical tests and software.

\section{Results}

Histology of NMSC. Fig. 1 shows a representative histological picture of tumor tissue from formalin-fixed paraffin-embedded skin tissue sections.

Genomic DNA extraction from FFPET. The purity and concentration of DNA are shown in Table I. This modified extraction methods produced good yields of DNA (above $10 \mathrm{ng} / \mu \mathrm{l}$ ), which were adequate for the PCR reactions. Purity of the extracted DNA range from 1.3-1.92. From touchdown PCR, 60 (67.4\%) of the extracted DNA were amplifiable whereas in RAPD PCR,
Table I. Purity and concentration range of extracted DNA.

\begin{tabular}{lrr}
\hline & $\mathrm{n}$ & $\%$ \\
\hline $\begin{array}{lrr}\text { Purity }(260 / 280) \\
1.7-2.0\end{array}$ & 60 & \\
$1.5-1.69$ & 22 & 67.4 \\
$<1.5$ & 7 & 7.9 \\
Concentration $(\mathrm{ng} / \mu \mathrm{l})$ & & \\
$10-30$ & 45 & 50.5 \\
$31-50$ & 27 & 30.3 \\
$51-99$ & 10 & 11.2 \\
$100-200$ & 5 & 5.6 \\
$>200$ & 2 & 2.2 \\
\hline
\end{tabular}

$68(76.4 \%)$ of the DNA were successfully amplified with either one of the three primers used. Taken as a whole, $85(95.5 \%)$ of the DNA extracted were successfully amplified with either one of the PCR used in this study.

Touchdown PCR for polymorphism detection. Amplification with primer specific for Arg allele yielded banding size of $141 \mathrm{bp}$, whereas the product of the Pro allele gave $177 \mathrm{bp}$, as demonstrated in Fig. 2. Sixty out of 89 of the DNA extracted were successfully amplified using touchdown PCR. NMSC FFPE (70\%) possessed Arg/Arg, 20\% with Pro/Pro and 10\% with Arg/Pro. Twenty-four (72.7\%) of BCC possessed Arg/Arg genotype, 7 (21.2\%) were Pro/Pro and 2 (6.1\%) were Arg/ 


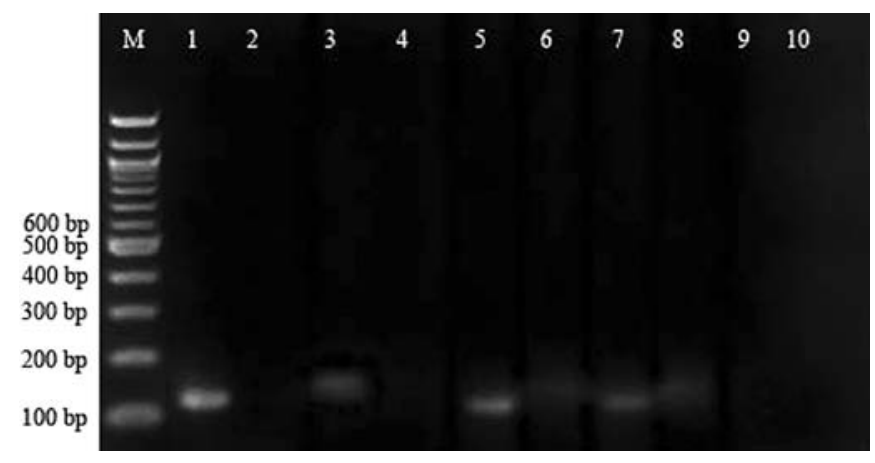

Figure 2. Representative gel picture obtained using touchdown PCR. M is the 100-bp molecular weight marker. Lanes 1 and 2 are from a sample that demonstrate arginine homozygous, lanes 3 and 4 are from a sample that demonstrate proline homozygous and lanes 5 and 6 are from a sample that demonstrate heterozygous genotype. Lanes 7 and 8 are the positive control for arginine and proline, respectively. Lanes 9 and 10 are the negative control for arginine and proline, respectively.

Pro. While for SCC, 18 (66.7\%) were Arg/Arg, 5 (18.5\%) were Pro/Pro and 4 (14.8\%) were Arg/Pro. Arg/Arg genotype was the most frequent genotype in both types with an apparent increase in frequency of Arg/Pro genotype in SCC compared to BCC (14.8 vs. $6.1 \%)$. Sixteen $(84.2 \%)$ of female patients were Arg/Arg, 2 (10.5\%) were Arg/Pro and 1 (5.3\%) were Pro/ Pro. Whereas for male, 26 (65\%) were Arg/Arg, 10 (25\%) were Pro/Pro and 4 (10\%) were Arg/Pro. There was a decrease in the frequency of Arg/Arg in male compared with female (65 and $84.2 \%$, respectively), but it still remains the most frequent genotype in both gender. There was also an increase in Pro/Pro in male as compared with female; 25 and $5.3 \%$, respectively. As for Chinese subjects, there were 26 (72.2\%) with Arg/Arg, 7 (19.4\%) were Pro/Pro and 3 (8.33\%) were Arg/Pro. On the other hand, 11 (61.1\%) from Malay subjects were Arg/Arg, 5 (27.8\%) were Pro/Pro and 2 (11.1\%) were Arg/Pro. Among Indian subjects, 4 (80\%) were Arg/Arg, 1 (20\%) was Arg/Pro. None from the Indian subjects was Pro/Pro but this can be due to low sample size for this particular category. There was also a case where the subject was not from the three races mentioned above possessed Arg/Arg. It is obvious that regardless of race, $\mathrm{Arg} / \mathrm{Arg}$ was the most frequent genotype found in this selected Malaysian NMSC patients. Twenty-nine (67.4\%) of the tumors located on face or head area were Arg/Arg, 10 (23.3\%) were Pro/Pro and 4 (9.3\%) were Arg/Pro. Whereas for tumor located on area other than face and head, 7 (70\%) were Arg/Arg, 2 (20\%) were Arg/Pro and 1 (10\%) was Pro/Pro. Pro/ Pro seemed to be more frequent in cases where the tumor was located in face or head area. In addition, face or head area was considered to be directly exposed to sun whereas other part of the body was assumed to be indirectly exposed. Based on this assumption, Pro/Pro became the most frequent genotype seen in individuals whose tumor lesion was directly exposed to sun. But still, Arg/Arg was the most frequent genotype found in both locations. In cases in which the tumor locations were not determined, 6 (85.7\%) were Arg/Arg and 1 (14.3\%) was Pro/Pro. No subjects possessed Arg/Pro in this undetermined group. Additionally, the genotype frequency in subjects age $<40$-years were $3(42.9 \%)$ for both the homozygotes (Arg/Arg and Pro/Pro) and 1 (14.3\%) Arg/Pro. For the 40 to 60-year- old group, 11 (68.8\%) were Arg/Arg, 3 (18.8\%) were Pro/Pro and 2 (12.5\%) were Arg/Pro. Twenty-one (80.8\%) were Arg/ Arg, 4 (15.4\%) were Pro/Pro and 1 (3.8\%) were Arg/Pro in $>60$-year old age group. Whereas in cases where the age was not determined, 7 (63.6\%) were Arg/Arg and 2 (18.2\%) for both Arg/Pro and Pro/Pro. There was an apparent increase in frequency of Arg/Pro genotype with increasing age; 42.9, 68.8 and $80.8 \%$ in $<40,40-60$ and $>60$-year-old age group, respectively. But on the contrary, frequency of Pro/Pro decreased with increasing age; 42.9, 18.8 and 15.4\%. Frequency of Arg/ Pro was also decreased with increasing age with the frequencies of 14.3, 12.5 and 3.8\%. Purified PCR amplicons were further purified using the GENEALL ${ }^{\mathrm{TM}}$ GEL SV kit (General Biosystem, Korea) according to the manufacturer's protocol and sent to direct sequencing (1st Base, Malaysia). Sequences obtained were further analyzed using Basic Local Alignment Search Tools (BLAST) program from National Center for Biotechnology Information (NCBI) website.

Genotype frequencies of p53 codon 72 polymorphism and its association with NMSC. In total, there was no significant difference in the p53 codon 72 genotype frequencies between BCC and SCC when data were tested with Fisher's exact test using SPSS $14.0(\mathrm{P}=0.05)$. $\mathrm{P}$-value of $>0.05$ is considered as not significant. There were no significant associations between p53 codon 72 genotypes with gender, race, location of tumor and age group. There was an apparent increase in frequency of Arg/Pro genotype in SCC compared to BCC but it was not statistically significant ( 14.8 vs. $6.1 \%, \mathrm{P}=0.648)$. The genotype distribution was different in female and male, but did not differ significantly (Fisher's exact test, $\mathrm{P}=0.219$ ). Although Pro/Pro seemed to be more frequent in cases where the tumor was located on the face or head area (directly exposed to sun), it failed to reach statistical significance (Fisher's exact test, $\mathrm{P}=0.490$ ) level. The age-associated increase in Arg/Arg genotype distribution was evident but it did not reach statistical significance (Fisher's exact test, $\mathrm{P}=0.235$ ). This may be attributable to the limited patient number in each subgroup (Table II). The genotype distribution was similar in Chinese, Indian and Malays according to the statistical test (Fisher's exact test, $\mathrm{P}=0.711$ ) but it can be due to insufficient sample size for Indian subjects. The statistical analysis summary is demonstrated in Table II.

Association between demographic characteristics of subjects and histology of NMSC. Since there were no significant associations between p53 codon 72 genotypes with the gender, race, location of tumor and age group, additional statistical analysis was performed to evaluate whether there are significant associations among the demographic characteristics of the subjects. Subjects with incomplete data were excluded thus some number may not add up to total of $89 . \chi^{2}$ test as well as Fisher's exact test were used, with statistical significance was regarded at $\mathrm{P}$-value $<0.05$. There was no significant association in gender frequencies in regard of age groups, race, type of NMSC and tumor location. Eight (88.9\%) out of 9 subjects in $<40$-year-old group were male and only one $(11.1 \%)$ was female. For 40-60-year-old group, 11 (57.9\%) were female and $8(42.1 \%)$ were male while in $>60$-year-old group, 25 $(58.1 \%)$ were male and $18(41.9 \%)$ were female. In $<40$ as well 
Table II. Demographic characteristics, histological types of NMSC and p53 codon 72 polymorphism genotypes.

\begin{tabular}{|c|c|c|c|c|}
\hline \multirow[b]{2}{*}{ Total } & \multicolumn{3}{|c|}{ p53 codon 72 polymorphism } & \multirow[b]{2}{*}{ P-value } \\
\hline & $\begin{array}{c}\operatorname{Arg} / \operatorname{Arg}(\mathrm{n}=42) \\
\mathrm{n}(\%)\end{array}$ & $\begin{array}{c}\operatorname{Arg} / \operatorname{Pro}(\mathrm{n}=6) \\
\mathrm{n}(\%)\end{array}$ & $\begin{array}{c}\text { Pro } / \text { Pro }(\mathrm{n}=12) \\
\text { n }(\%)\end{array}$ & \\
\hline \multicolumn{5}{|c|}{ Histological types } \\
\hline $\mathrm{BCC}$ & $24(72.72)$ & $2(6.1)$ & $7(21.2)$ & \multirow[t]{2}{*}{ Fisher's exact test, 0.648} \\
\hline SCC & $18(66.7)$ & $4(14.8)$ & $5(18.5)$ & \\
\hline \multicolumn{5}{|c|}{ Age group (years) } \\
\hline$<40$ & $3(42.9)$ & $1(14.3)$ & $3(42.9)$ & \multirow[t]{3}{*}{ Fisher's exact test, 0.235} \\
\hline $40-60$ & $11(68.8)$ & $2(12.5)$ & $3(18.8)$ & \\
\hline$>60$ & $21(80.8)$ & $1(3.8)$ & $4(5.4)$ & \\
\hline \multicolumn{5}{|l|}{ Gender } \\
\hline Female & $16(84.2)$ & $2(10.5)$ & $1(5.3)$ & \multirow[t]{2}{*}{ Fisher's exact test, 0.219} \\
\hline Male & $26(65)$ & $4(10)$ & $10(25)$ & \\
\hline \multicolumn{5}{|l|}{ Race } \\
\hline Chinese & $26(72.2)$ & $3(8.3)$ & $7(19.4)$ & \multirow[t]{4}{*}{ Fisher's exact test, 0.711} \\
\hline Indian & $4(80)$ & $1(20)$ & $0(0)$ & \\
\hline Malay & $11(61)$ & $2(11.1)$ & $5(27.8)$ & \\
\hline Others & $1(100)$ & $0(0)$ & $0(0)$ & \\
\hline \multicolumn{5}{|c|}{ Location of tumor } \\
\hline Face/head & $29(67.4)$ & $4(9.3)$ & $10(23.3)$ & \multirow[t]{2}{*}{ Fisher's exact test, 0.490} \\
\hline Others & $7(70)$ & $2(20)$ & $1(10)$ & \\
\hline
\end{tabular}

BCC, basal cell carcinoma; SCC, squamous cell carcinoma. Some numbers may not add up to the total due to lack of information.

as $>60$-year-old age group, males outnumbered females $(88.9$ vs. $11.1 \%$ and 58.1 vs. $41.9 \%$, respectively) but for group of 40-60 year old, females were more frequent (57.9 vs. $42.1 \%$ ). However, it failed to be statistically significant (Fisher's exact test, $\mathrm{P}=0.065)$. In Chinese subjects, $33(66 \%)$ were males and 17 (34\%) were females while for Indian, 5 (71.4\%) were females and $2(26.6 \%)$ were male. There were $16(57.1 \%)$ males and $12(42.9 \%)$ females in Malay subjects. In two cases from other races, both were females. Males were predominant in Chinese and Malay subjects (66 vs. $34 \%$ in Chinese and 57.1 vs. $42.9 \%$ in Malay, respectively). It is the opposite for Indian and other races, where females were more frequent (71.4 vs. $26.6 \%$ in Indian and $100 \%$ females in other races, respectively) but not significantly different (Fisher's exact test, $\mathrm{P}=0.086$ ). Twenty-nine (58\%) were males and $21(42 \%)$ were females in BCC subjects whereas there were 22 (59.5\%) males and $15(40.5 \%)$ females among SCC subjects. Males were more frequent in BCC as compared to female (58 vs. $42 \%$ ) and it was also the same for SCC (59.5 males and $40.5 \%$ females) but did not reach statistical significance $\left(\chi^{2}\right.$ test, $\left.\mathrm{P}=0.891\right)$. According to the location of tumor, $35(56.5 \%)$ males were categorized into face or head group whereas females were 27 (42\%). On the other hand, $9(64.3 \%)$ males and $5(35.7 \%)$ females were categorized into other locations group. Once again, males predominated each group location but this finding was not statistically significant $\left(\chi^{2}\right.$ test, $\left.\mathrm{P}=0.592\right)$. In analysis of age group frequencies for each race, for Chinese 29 (69\%) were above 60 years old, 8 (19\%) were between 40-60 years old and
$5(11.9 \%)$ were below 40 years old. In Indian, 5 (83.3\%) aged between $40-60$, one subject (16.7\%) was over 60 years old and none below 40 years old. Furthermore, in Malay subjects, 6 (28.6\%) were in 40-60-year-old group while $4(19 \%)$ were in $<40$-year-old group. Two cases were from other race and both of them were from $>60$-year-old group. Group $>60$-year-old was more common in Chinese and Malay (69 and 52.4\%) whereas group 40-60-year old was the most frequent in Indian (83.3\%) but not statistically significant (Fisher's exact test, $\mathrm{P}=0.055$ ). In BCC subjects, $>60$-year-old group was predominant while for SCC, the prevalence of $>60$ and 40-60-year-old group was the same. There was a significant difference between the age group frequencies in each type of NMSC (Fisher's exact test, $\mathrm{P}=0.010$ ). Total of subjects aged $>60$ years old was significantly higher in BCC compared with SCC (75.6 vs. 40\%). For subjects aged between 40-60 years old, SCC subjects were significantly higher than BCC subjects (40 vs. 17.1\%). Whereas in subjects aged $<40$ year old, SCC subjects also outnumbered the BCC subjects (20 vs. $7.3 \%)$. Further analysis revealed that $\mathrm{BCC}$ was more common in individual aged $>60$ year old while in SCC, individual aged $<60$ contributed to more than half of the cases. In subjects aged $<40$ years old, $6(66.6 \%)$ were SCC patients and $3(33.3 \%)$ were BCC patients and in 40-60-year-old group, SCC patients contributed 12 cases $(63.2 \%)$ while BCC gave rise to 7 cases $(36.8 \%)$. Thirty-one (72.1\%) from the subjects aged $>60$ year old were represented with BCC while $12(27.9 \%)$ were SCC. All these finding were statistically significant (Fisher's exact test, $\mathrm{P}=0.010$ ). When the 
Table III. Demographic characteristics and histological types of NMSC.

\begin{tabular}{lccc}
\hline & $\begin{array}{c}\text { BCC (total } \mathrm{n}=51)^{\mathrm{a}} \\
\mathrm{n}(\%)\end{array}$ & $\begin{array}{c}\mathrm{SCC}(\text { total } \mathrm{n}=38)^{\mathrm{a}} \\
\mathrm{n}(\%)\end{array}$ & P-value \\
\hline $\begin{array}{l}\text { Age (years) } \\
<40\end{array}$ & $3(33.3)$ & $6(66.6)$ & Fisher's exact test, 0.010 \\
$40-60$ & $7(36.8)$ & $12(63.2)$ & \\
$>60$ & $31(72.1)$ & $12(27.9)$ & \\
Race & & & Fisher's exact test, 0.006 \\
Chinese & $33(64.7)$ & $18(35.3)$ & \\
Indian & $0(0)$ & $7(100)$ & \\
Malay & $16(57.1)$ & $12(42.9)$ & \\
Others & $1(50)$ & $1(50)$ & $\chi^{2}$ test, 0.000 \\
Location of tumor & & $22(61.1)$ & \\
Face/head & $42(100)$ & $14(38.9)$ & \\
Others & $0(0)$ & & \\
\hline
\end{tabular}

BCC, basal cell carcinoma, SCC, squamous cell carcinoma. aSome numbers may not add up to the total due to lack of information.

age group frequencies were compared with tumor location, $>60$-year-old age group predominated in both groups of locations. However, no significant relationship was found (Fisher's exact test, $\mathrm{P}=0.786)$. Twenty-nine (58\%) of NMSC patients whose tumor located on the face or head area were aged $>60$ years old, followed by 15 (30\%) from 40-60-year-old group and 6 were from $<40$ year-old-group (12\%). For tumor located at other sites than face and head, $6(60 \%)$ aged $>60$ years old and $2(20 \%)$ for each 40-60-and <40-year-old group. Analysis of race frequencies in each type of NMSC obtained was statistically significant (Fisher's exact test, $\mathrm{P}=0.006$ ). In BCC subjects, 33 (66\%) were Chinese, followed by 16 (32\%) Malay, $1(2 \%)$ other race and none from Indian. On the other hand, in SCC subjects 18 (47.4\%) were Chinese, 12 (31.6\%) were Malay, 7 (18.4\%) were Indian and 1 (2.6\%) from another race. Distribution of races in each type of NMSC were significantly different. Further analysis revealed that in Chinese subjects, 33 (64.7\%) developed BCC whereas 18 (35.3\%) were diagnosed with SCC. All of Indian subjects were SCC patients and no case represented BCC. Among Malay subjects, 16 (57.1\%) were BCC patients and $12(42.9 \%)$ were SCC patients. The distribution in each type NMSC were 50\% in subjects form other races. This indicating a statistically significant difference in the frequency of BCC and SCC in each race (Fisher's exact test, $\mathrm{P}=0.006)$. Chinese subjects $(65.1 \%)$ developed NMSC on the face or head area, followed by 15 (23.8\%) Malay, $6(9.5 \%)$ Indian and $1(1.6 \%)$ from other races. While for tumor located at other sites, 7 (50\%) were Malay 5 (35.7\%) were Chinese, $1(7.1 \%)$ were Indian and $1(7.1 \%)$ was another race. Chinese subjects outnumbered other races in face or head group (65.1\%) whereas Malay were more likely to develop NMSC in other location (50\%). However, there was no significant relationship between race frequencies and locations of the tumor (Fisher's exact test, $\mathrm{P}=0.092)$. For tumor located on the face or head, 42 $(65.6 \%)$ were BCC subjects and $22(34.4 \%)$ were SCC subjects. While for the other group, 14 (100\%) were derived from SCC patients and none from BCC. Statistical analysis revealed that there was significant association between type of NMSC and tumor location. Further analysis found that in 42 (100\%) BCC cases, the tumor was located on the face or head. On the other hand in SCC cases, $22(61.1 \%)$ of the tumors were located on the face or head and 14 (38.9\%) were located at other sites. These finding were statistically significant $\left(\chi^{2}\right.$ test, $\left.\mathrm{P}=0.000\right)$. Summary of the statistical analysis is shown in Table III, with only significant findings presented.

$R A P D-P C R$. Genome regions amplified by OPO-09, OPO-12 and OPO-20 primers differed from each other and the results revealed that $66(74.2 \%)$ samples were successfully amplified using OPO-20 primer and 57 (64\%) samples by using OPO-12 primer. OPO-09 primer gave the least amplification, only 19 (21.3\%) samples produced DNA fragments upon gel electrophoresis. Several DNA segments amplified in each sample, with some segments were amplified from one individual but not the other. For example, a 500-1000 bp DNA segment was amplified by primer OPO-09 from a sample (lane number 6) but not from the others (Fig. 3A). Twenty-one (23.6\%) samples gave no amplification with any of the primers. For OPO-09 (Fig. 3A), no consistent band was seen on the agarose gel. Perhaps, this primer is not suitable for these samples. As for the OPO-12 (Fig. 3B), more bands were obtained but the patterns were not obvious. On the other hand, amplification with OPO-20 (Fig. 3C) resulted in several patterns being produced. A band of $\sim 1.4 \mathrm{~kb}$ was produced in more than half of the samples, indicating a sequence similarity was shared between these samples. These findings can be further analyzed for biomarker development. From a total of 89 samples, 18 (20.2\%) were successfully amplified by these three arbitrary primers. Fig. 4 shows the banding patterns for the 18 samples. To generate a dendrogram, RAPDistance software was used. A similarity matrix was calculated using Jaccard and Dice coefficient. The similarity coefficients for 18 samples obtained with RAPD markers ranged from 0.014 to 0.484 for Jaccard coefficient and 0.046 to 0.471 for Dice coefficients. The dendrogram, based on 

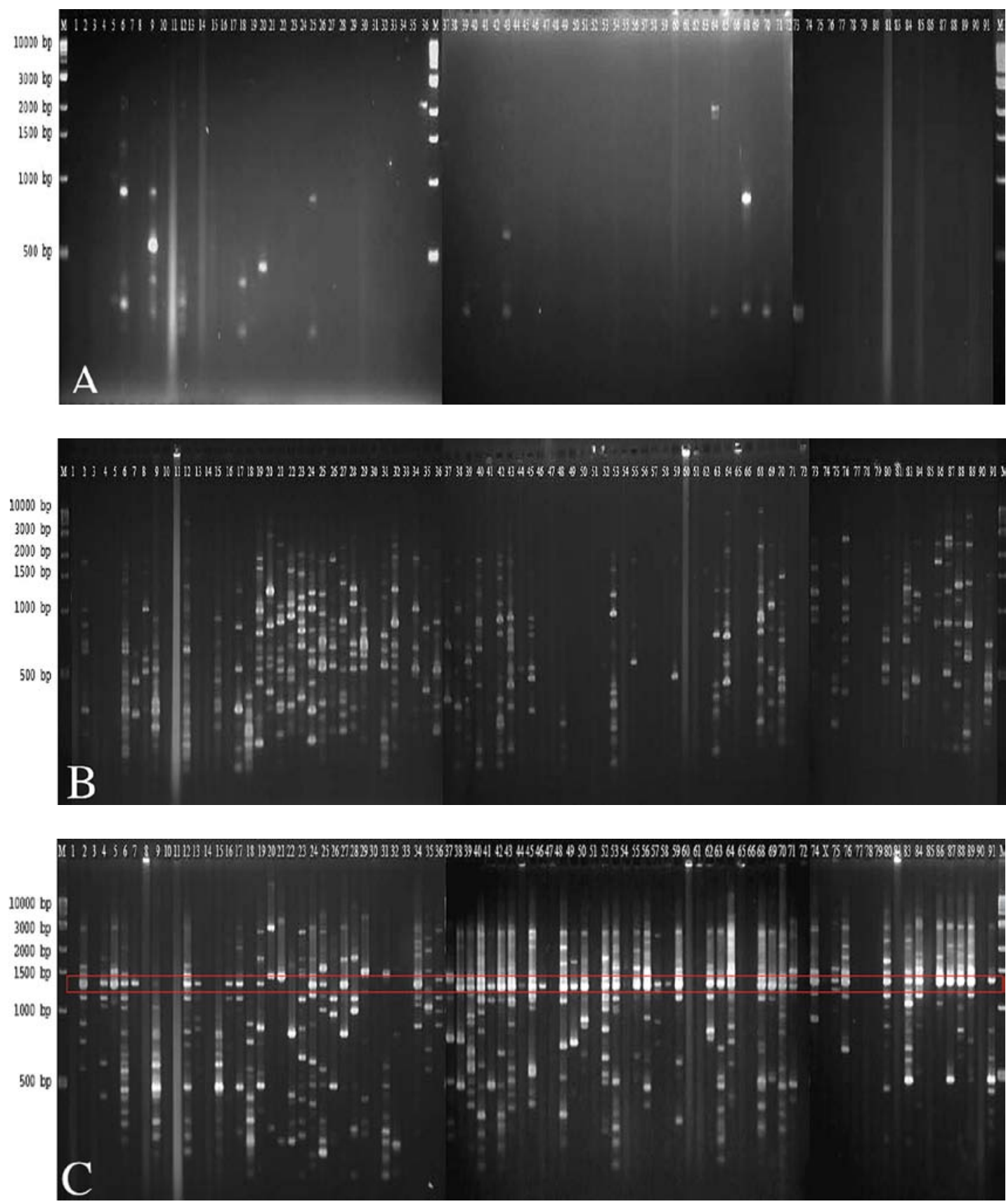

Figure 3. Agarose gel picture for amplification with A, OPO-09, B, OPO-12 and C, OPO-20, respectively. M, the molecular weight marker using 1-kb ladder while the numbers on the top represent sample number.

RAPD data, showed a clear distinction into major and minor clusters. The dendrogams obtained using both coefficients showed the presence of three main clusters having four, seven and seven samples in each, respectively, as in Fig. 5.

\section{Discussion}

Malaysia is a multiracial temperate developed country with incidence of NMSC approaching $4 \%$ of all cancers in males and $2.7 \%$ in females from peninsular Malaysia. These data concluded that NMSC was categorized as the ninth most frequent cancers in males and tenth in female (3). So far, there is limited information on the frequency of that polymorphism in normal Malaysian population and NMSC. p53 is one of the most important tumor suppressor genes. Germline mutations in this gene lead to the Li-Fraumeni syndrome while polymorphisms modulate the risk of several types of cancer. p53 codon 72 polymorphism lies in a proline-rich region, which is important for its ability to induce apoptosis (32). Proline is a stronger inductor of p21, one of p53 effectors in the cell cycle checkpoint (12). On the other hand, arginine is able to induce 5-10 times more apoptosis than proline, which is explained in part by a higher ability of arginine to localize to the mitochondria (33).

In this study, the statistical analysis revealed that there is no direct association between $\mathrm{p} 53$ codon 72 polymorphism with the type of NMSC and demographic characteristics of the selected Malaysian patients. Only few studies have been 

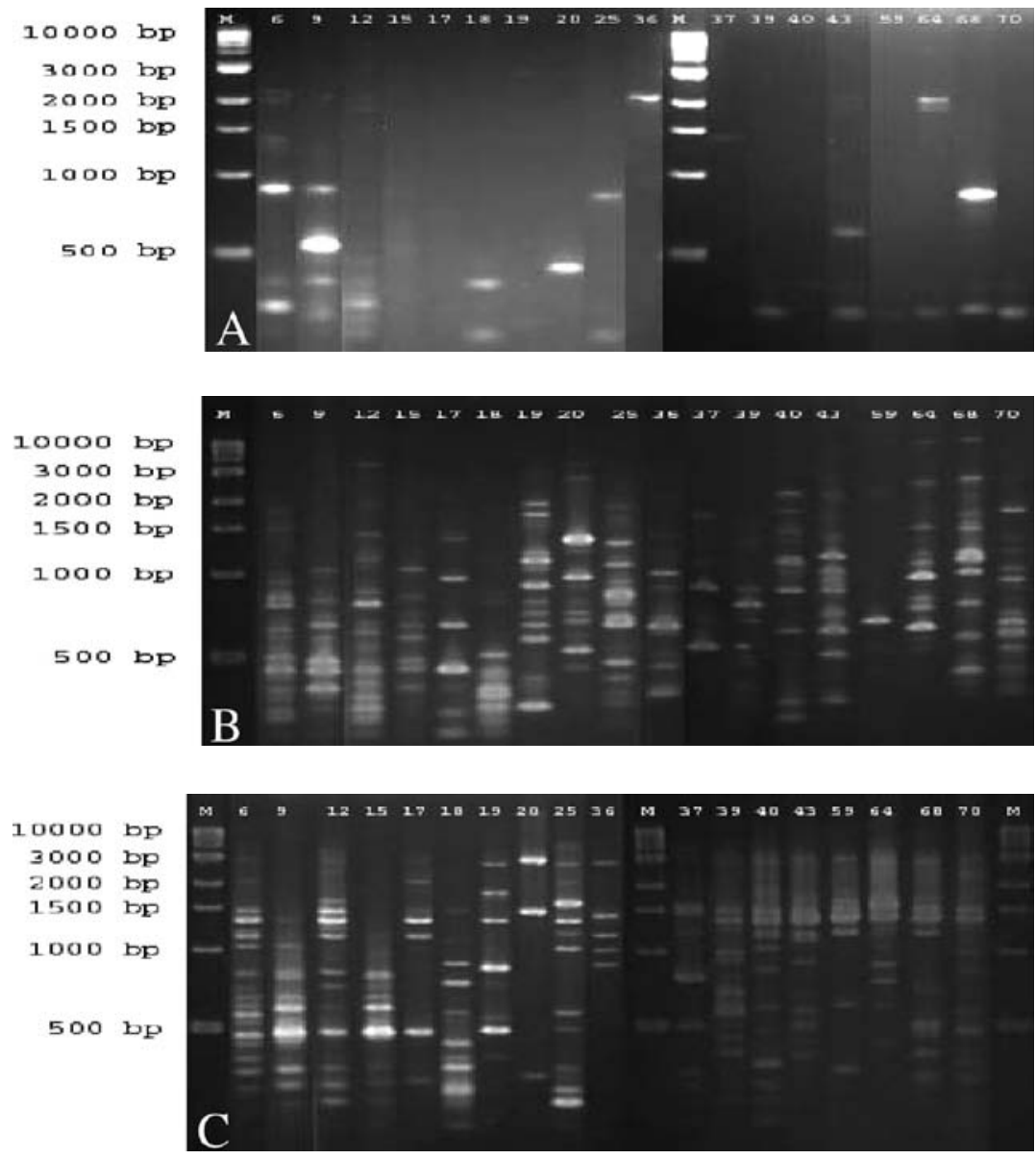

Figure 4. Banding patterns produced by A, OPO-09, B, OPO-12 and C, OPO-20, respectively, from the 18 samples. M, the molecular weight marker. Numbers on top of the pictures represent designated sample's number while missing numbers indicate that the samples were not successfully amplified with the three primers.

A

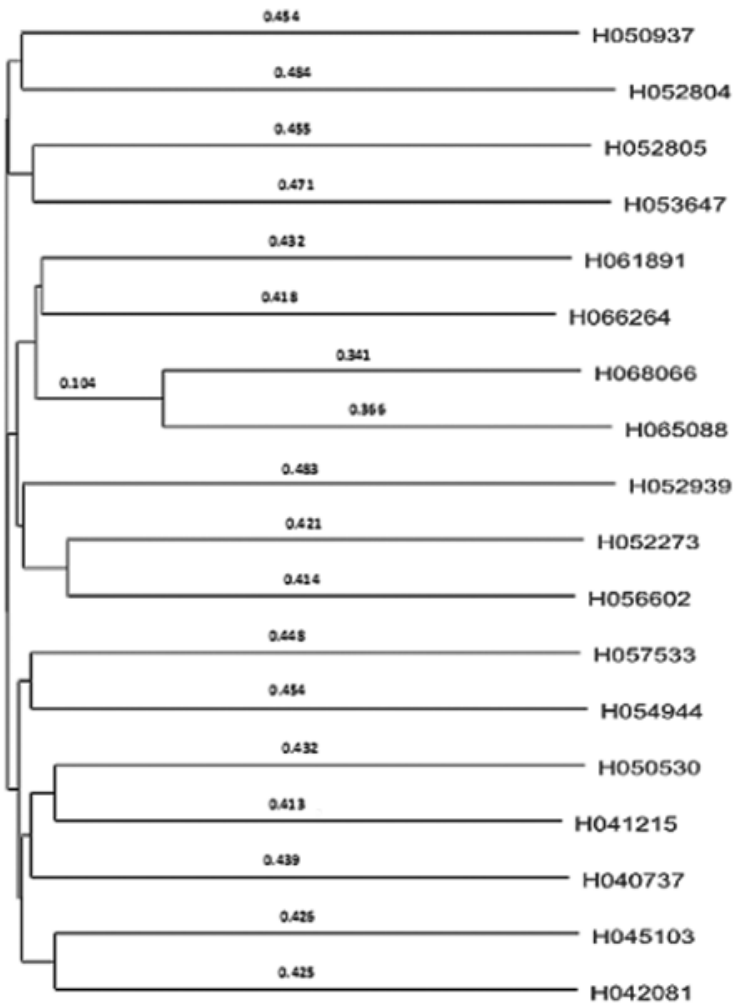

B

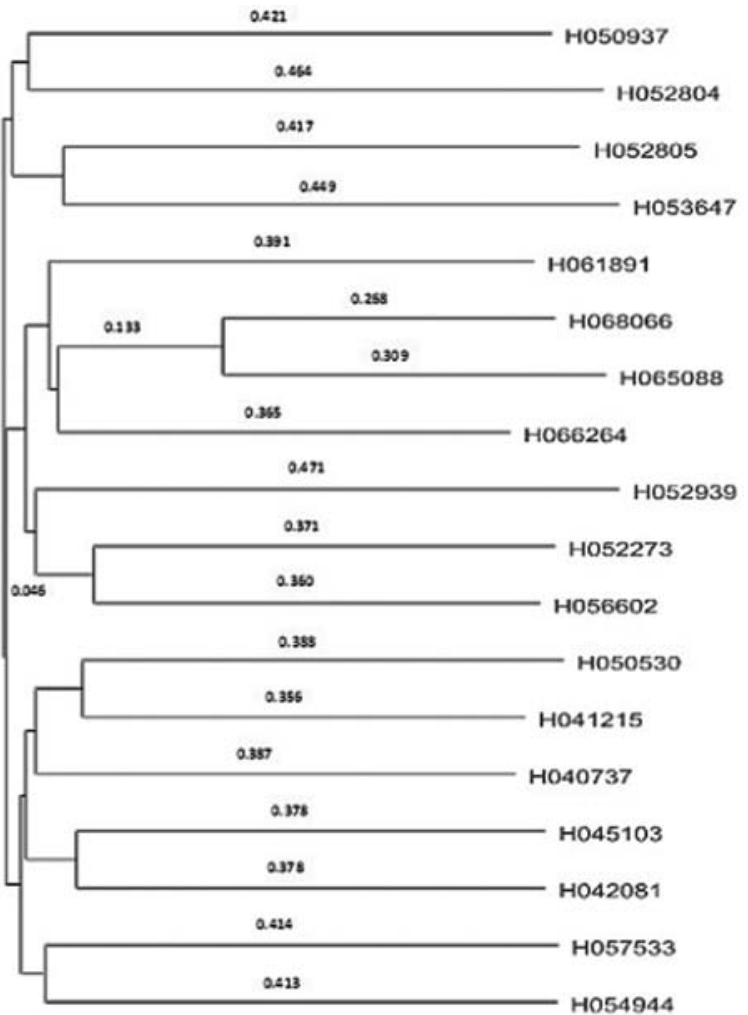

Figure 5. Dendrogram generated using (A) Jaccard and (B) Dice coefficient. 
conducted to find these association since most of the studies tried to analyze the associations of the polymorphism in cancer patients and healthy population $(31,34)$. Moreover, Arg/ Arg genotype was found dominant in both types of NMSC. No studies supported this finding so far, at least in Malaysian patients. This finding suggests that p53 codon 72 genotype did not determine whether an individual will develop BCC or SCC since the genotype distributions were not significantly different. Although no significant difference was found in the genotype frequency between female and male, the frequency of Arg/Arg in female NMSC was found to be high (84.2\%). In studies conducted in Asian cervical cancer patients, this genotype frequency was found to be relatively low; $40 \%$ (35) in Korean women; $44.8 \%$ (36) in Japanese women; $31 \%$ in Hong Kong women (37) and $27 \%$ in Indian women (38). Whether this genotype can be attributed to NMSC risk in female requires further investigation since different types of cancer influenced the polymorphism differently. However, at least in this selected studied population, frequency of p53 Arg/Arg in female was almost 8-fold of other genotypes. A non-significant age-associated increase in the Arg/Arg genotype frequency was also observed. p53 can act through several pathways when reacting to cellular stress. Apoptosis, cell cycle arrest at the G1 checkpoint, and cellular senescence are all mechanisms triggered by activated p53 (39). These mechanisms are all beneficial when the organism is young, but in older organisms, such effects probably reduce longevity and augment cancer risk (40). In accordance with this concept, p53 accelerates aging when responding to cellular stress (41). The Arg allele of this polymorphism increases p53-induced apoptosis, whereas the Pro allele produce cell cycle arrest in the G1 phase (33). Orsted et al suggested that Arg/Pro heterozygotes and Pro/ Pro versus Arg/Arg homozygotes have reduced mortality, which could result from a generally decreased aging process caused by decreased proapoptotic activity and increased cell cycle-arresting abilities of p53 (42). Unfortunately, no studies assessed the age-associated changes regarding codon 72 genotype distribution in NMSC. However, the relationship between codon 72 genotype and patient age have been reported in some previous studies on lung cancer patients. Wang et al studied 194 lung cancer patients and 152 non-cancer controls (13). They found that patients with Pro/Pro genotype had an odds ratio of $2.63(95 \% \mathrm{CI}, 1.22-5.68 ; \mathrm{P}=0.01)$ higher than those with the other genotypes to be diagnosed with lung cancer at earlier ages. Although they did not mention the association of patient age and Arg/Arg genotype distribution, it was evident from their data that $\mathrm{Arg} / \mathrm{Arg}$ genotype occurred in $40 \%$ of 150 cancer cases who were aged 60 or over, compared with $27.8 \%$ of 36 who were $<60$. In contrast, in non-cancer controls, there were $29.5 \%$ of 112 and $35 \%$ of 40 for those aged 60 or over and those younger than 60 , respectively. The mechanisms which lead to the age-associated increase of codon $72 \mathrm{Arg}$ p53 in NMSC are not clear. The preferential retention of codon 72 Arg p53 has been reported in esophageal squamous cell carcinoma (43) and this could lead to an increased frequency of $\mathrm{Arg}$ allele in cancer patients $>60$ years old. Data from the current study does not really support this mechanism because there is no data on the healthy subject with the same age group. The increased frequency of codon 72 Arg p53 was not significantly associated with patient age in NMSC patients and whether there is a significant difference between cancer and non-cancer patients has to be investigated. The most important risk factor of NMSC is solar UV radiation whereas ethnicity, color of unexposed skin, latitude, pattern and amount of sun exposure, other radiations, Arsenic exposure, Xeroderma pigmentosum, Bazex syndrome, and Gorlin's syndrome are other minor risk factors in the common population (44). As can be seen among the sunlight exposed tumor location (face or head area) of this study, the Arg allele frequency have decreased compared to other areas which are less exposed to sunlight. Since this finding is not statistically significant, p53 codon 72 genotype does not determine the tumor location developed in NMSC, whether at sun-exposed or non sun-exposed area. Bendesky et al irradiated with UVB isolated lymphocytes from subjects of their case-control study, with the three different p53 genotypes (34). They found that cells harboring at least one Arg allele had a significantly higher frequency of apoptotic cells than Pro homozygous cells but statistical analysis proved that Arg polymorphism was not associated with BCC, SCC, or NMSC. Their study suggested that in vitro, at least in Mexican NMSC, individuals possessing Arg allele (either homozygous or heterozygous) were less prone to this cancer compared with that of Pro allele. However, since in the recent study no information on the genotype frequencies in Malaysian healthy population is available, the risk of developing NMSC in individual with different p53 codon 72 genotypes cannot be determine thus demanding further research and analysis. p53 codon 72 polymorphism shows a latitude related distribution; i.e., higher prevalence of Pro allele in high latitude areas (31). It is usually concluded that dark skinned populations have a higher frequency of the Pro allele. This finding is not in agreement with this recent study. In selected Malaysian NMSC, the frequencies of the Pro/Pro genotype in Indian subjects was less than other races (Chinese and Malays). None of this group possesses Pro/Pro and only 20\% possessing Arg/Pro were lower than that of Arg allele and Arg/Arg genotype. However, this is most likely to be associated with the genes, not with skin color itself and the sample size is small thus not representing the whole Indian population.

Demographic characteristics analysis revealed that there were significant differences obtained regarding types of NMSC with respect to age-group, tumor location and races. Statistical analysis proved that there is an increase in frequency of BCC cases with increasing age. This result is supported by Carr et al that incidence of BCC increases with increasing age and the diagnosis is quite uncommon before the fourth decade of life (45). Whereas for SCC, the distribution according to age group was quite similar. It appears that among these two types, BCC more frequently occurs in older patients but SCC risk does not really modified by age. Even though solar UV radiation is the etiology for both types (1), cumulative sun exposure seems to have a strong influence on $\mathrm{BCC}$ incidence. As a person gets older, there is more chance UV exposure contributing to its cumulative effects on skin cancer development. Ethnicity encompasses both skin type and sociocultural differences (46). Thus, both inherent genetic differences and varying environmental exposure to UV radiation can account for the ethnic differences in this study. For the degree of fairness among ethnics in Malaysia, Chinese is the fairest, followed by Malay and Indian usually has the darkest 
skin color. None of Indian subjects in this study was diagnosed with $\mathrm{BCC}$, contributing to statistically significant finding in frequency of type of NMSC according to race. It is obvious from this statistical analysis that Indians are more likely to develop SCC than BCC. BCC of the skin mainly considered a disease of fair skinned people (1). In worldwide incidence, prevalence of $\mathrm{BCC}$ is higher than SCC but it thought to be a bias since most of the studies are conducted in white populations. Pfister also confirmed that SCCs are more common in darker skin population (47). The standardized ratio of $\mathrm{BCC}$ to SCC is roughly 4:1 (48). For all BCC cases, the tumor was located on the face or head area, which are also the areas which are directly exposed to sun. This is in agreement with Carr et al that the lesions may arise at any site but are most commonly located on sun-exposed areas, particularly the head and neck (45). As for the SCC, the tumor was found in both locations. The anatomic location of SCC is primarily on sun-exposed areas and in a study of patients dying of SCC, only $3.5 \%$ of primary tumors were on routinely covered areas of the trunk and the remainder were on exposed areas easily viewed during physical examination (49). The next most at risk area is the extremities (50). Some disagreement exists regarding exactly which parts of the head and neck are most at risk. Australian data suggest that the so-called 'less-exposed face' (area within the orbit and nasolabial fold) may be a more common site for SCC than the 'more-exposed face' (ears, nose, and cheeks) (51). These findings are statistically significant suggesting that type of NMSC determine where the malignant lesion will develop; either in directly sun-exposed area or the opposite. Moreover, Brenna et al concluded that the controversial data found by the different studies have been attributed to ethnic differences, but other potential confounding factors should be considered, including the sample size, the source of DNA, and the detection techniques use (52).

In RAPD, analysis on each coefficient proved that cluster produced by Jaccard coefficient was better compared with Dice. The similarity that was shared among the 18 samples was the location of the tumor. Malignant lesions in all 18 subjects were located in the area directly exposed to sun. Amplifications by RAPD showed that each single primers of arbitrary sequence can be used to amplify genomic DNA segments, and that polymorphisms can be detected between the amplification products of different individuals. Single primer of arbitrary sequence can be used to amplify genomic DNA segments, and that polymorphisms can be detected between the amplification products of different individuals (53). Study reported by Ribeiro et al indicated that genome regions amplified by RAPD primers were altered in all kinds of skin tumors of all patients, including melanocytic nevus and actinic keratosis, compared to normal leukocyte DNA (54). These findings also indicated a tendency to sequence deletions in malignant melanoma, and to amplifications in BCC, suggesting tumor genome rearrangements, and/or mutations that lead to new primer annealing sites.

Our study suggests that $\mathrm{Arg} / \mathrm{Arg}$ genotype might affect the risk of NMSC in Malaysian population since it is the most common genotype seen in analysis according to histology of NMSC and demographic characteristics. A dysfunctional p53 protein may lose its tumor suppressive and cell cycle arrest-inducing effects thus the altered protein will be non- functional or less functional in apoptosis induction. Different cancers have a different percentage of $\mathrm{p} 53$ polymorphism, therefore, the impact of the $\mathrm{p} 53$ codon 72 polymorphism upon susceptibility to particular cancer could depend on cancer subtype with a different percentage of p53 polymorphisms. Regarding the detection technique used, the optimized touchdown PCR condition able to detect codon 72 p53 polymorphism with $67.4 \%$ success rate. Distribution of p53 codon 72 genotype were $70 \% \mathrm{Arg} / \mathrm{Arg}$, 20\% Pro/Pro and 10\% Arg/ Pro. NMSC types and demographic characteristics did not influence genotypes distribution. On the other hand, BCC and SCC distribution was influenced by age group, race and tumor location. The RAPD technique may reveal unknown genes or DNA sequences associated with tumor development and progression, and represent a practical and low-cost method to differentiate normal from tumor tissues thus permitting its application in preliminary clinical diagnosis and prognosis. The present research is focused on correlating single gene mutations with various clinicopathological features, but the pattern of mutations in a combination of genes will probably be more useful.

\section{Acknowledgements}

The authors thank Associate Professor Saidi Moin for the guidance on statistical analysis. This study was supported under the Universiti Putra Malaysia Research University Grant Scheme (04-05-10-1109RU) and National Cancer Council Malaysia funding. Authors would like to extend their deepest appreciation to Hospital Universiti Kebangsaan Malaysia (HUKM) for the samples and Department of Biomedical Sciences (UPM) for the support, facilities and funding.

\section{References}

1. Diepgen TL and Mahler V: The epidemiology of skin cancer. $\mathrm{Br}$ J Dermatol 146: 1-6, 2002.

2. Housman TS, Feldman SR, Williford PM, Fleisher Jr AB, Goldman ND, Acostamadiedo JM and Chen GJ: Skin cancer is among the most costly of all cancers to treat for the Medicare population. J Am Acad Dermatol 48: 425-429, 2003.

3. Lim GCC and Halimah Y (eds): Second Report of the National Cancer Registry. Cancer Incidence in Malaysia 2003. National Cancer Registry, Kuala Lumpur, 2004.

4. Albert MR and Weinstock MA: Keratinocyte carcinoma. CA Cancer J Clin 53: 292-302, 2007.

5. Tilli CM, Van Steensel MA, Krekels GA, Neumann HA and Ramaekers FC: Molecular aetiology and pathogenesis of basal cell carcinoma. Br J Dermatol 152: 1108-1124, 2005.

6. Wong CS, Strange RC and Lear JT: Basal cell carcinoma. BMJ 327: 794-798, 2003.

7. May P and May E: Twenty years of $\mathrm{p} 53$ research: structural and functional aspects of the p53 protein. Oncogene 18: 7621-7636, 1999.

8. Walker KK and Levine AJ: Identification of a novel p53 functional domain that is necessary for efficient growth suppression. Proc Natl Acad Sci USA 93: 15335-15340, 1996.

9. Venot C, Maratrat M, Dureuil C, Conseiller E, Bracco L and Debussche L: The requirement for the proline rich functional domain for mediation of apoptosis is correlated with specific PIG3 gene transactivation and with transcriptional repression. EMBO J 17: 4668-4679, 1998.

10. Zhu J, Jiang J, Zhou W, Zhu K and Chen X: Differential regulation of cellular target genes by p53 devoid of the PXXP motifs with impaired apoptotic activity. Oncogene 18: 2149-2155, 1999. 
11. Matlashewski G, Tuck S, Pim D, Lamb P, Schneider J and Crawford LV: Primary structure polymorphism at amino acid residue 72 of human p53. Mol Cell Biol 7: 961-963, 1987.

12. Thomas M, Kalita A, Labrecque S, Pim D, Banks L and Matlashewski G: Two polymorphic variants of wild-type p53 differ biochemically and biologically. Mol Cell Biol 19: 1092-1100, 1999.

13. Wang YC, Chen CY, Chen SK, Chang YY and Lin P: p53 codon 72 polymorphism in Taiwanese lung cancer patients: association with lung cancer susceptibility and prognosis. Clin Cancer Res 5: 129-134, 1999

14. Kawajiri K, Nakachi K, Imai K, Watanabe J and Hayashi S: Germ line polymorphisms of p53 and CYP1A1 genes involved in human lung cancer. Carcinogenesis 14: 1085-1089, 1993.

15. Fan R, Wu MT, Miller D, Wain JC, Kelsey KT, Wiencke JK and Christiani DC: The p53 codon 72 polymorphism and lung cancer risk. Cancer Epidemiol Biomark Prev 9: 1037-1042, 2000.

16. Sjalander A, Birgander R, Hallmans G, et al: $\mathrm{p} 53$ polymorphisms and haplotypes in breast cancer. Carcinogenesis 17: 1313-1316, 1996.

17. Tenti $P$, Vesentini N, Rondo-Spaudo M, Zappatore R, Migliora $P$, Carnevali L and Ranzani GN: p53 codon 72 polymorphism does not affect the risk of cervical cancer in patients from northern Italy. Cancer Epidemiol Biomark Prev 9: 435-438, 2000.

18. Storey A, Thomas M, Kalita A, et al: Role of a 553 polymorphism in the development of human papillomavirus-associated cancer. Nature 393: 229-234, 1998.

19. McGregor JM, Harwood CA, Brooks L, et al: Relationship between p53 codon 72 polymorphism and susceptibility to sunburn and skin cancer. J Invest Dermatol 119: 84-90, 2002.

20. Ong TM, Song B, Qian HW, Qian TW, Wu ZL and Whong WZ: Detection of genomic instability in lung cancer tissues by random amplified polymorphic DNA analysis. Carcinogenesis 19: $233-235,1998$

21. Maeda T, Jikko A, Hiranuma $\mathrm{H}$ and Fuchihata H: Analysis of genomic instability in squamous cell carcinoma of the head and neck using the random amplified polymorphic DNA method. Cancer Lett 138: 183-188, 1999.

22. Misra DAA, Sulaiman IM, Sinha S, Sarkar C, Mahapatra AK and Hasnain SE: Genetic alterations in brain tumors identified by RAPD analysis. Gene 206: 45-48, 1998.

23. Sood AK and Buller RE: Genomic instability in ovarian cancer: A reassessment using an arbitrarily primed polymerase chain reaction. Oncogene 13: 2499-2504, 1996.

24. Singh KP and Roy D: Identification of novel breast tumor-specific mutation(s) in the q11.2 region of chromosome 17 by RAPD/ AP-PCR fingerprinting. Gene 269: 33-43, 2001.

25. Papadopoulos S, Benter T, Anastassiou G, et al: Assessment of genomic instability in breast cancer and uveal melanoma by random amplified polymorphic DNA analysis. Int J Cancer 99: 193-200, 2002.

26. Zhang SH, Cong WM, Xian ZH, Dong H and Wu MC: Genomic instability in Hepatocellular carcinoma revealed by using random amplified polymorphic DNA method. J Cancer Res Clin Oncol 130: 757-761, 2004.

27. Xian ZH, Cong WM, Zhang SH and Wu HC: Genetic alteration of hepatocellular carcinoma by random amplified polymorphic DNA analysis and cloning sequencing of tumor differential DNA fragment. World J Gastroenterol 11: 4102-4107, 2005.

28. Scarra A, Moore PS, Rigaud G and Menestrina F: Genetic alternations in primary mediastinal $\beta$-cell lymphoma: an update. Leuk Lymphoma 41: 47-53, 2001.

29. Odero MD, Soto JL, Matutes E, et al: Comparative genomic hybridization and amplotyping by arbitrarily primed PCR in stage A B-CLL. Cancer Genet Cytogenetic 130: 8-13, 2001.

30. Greer CE, Wheeler CM and Manos MM: Sample preparation and PCR amplification from paraffin-embedded tissue. PCR Methods Appl 3: S113-S122, 1994.

31. Pezeshki A, Sari-Aslani F, Ghaderi A and Doroudchi M: p53 Codon 72 polymorphism in basal cell carcinoma of the skin. Pathol Oncol Res 12: 29-33, 2006.

32. Sakamuro D, Sabbatini P, White E and Prendergast GC: The polyproline region of $\mathrm{p} 53$ is required to activate apoptosis but not growth arrest. Oncogene 15: 887-898, 1997.
33. Dumont P, Leu JI, Della Pietra AC, George DL and Murphy M: The codon 72 polymorphic variants of p53 have markedly different apoptotic potential. Nat Genet 33: 357-365, 2003.

34. Bendesky A, Rosales A, Salazar AM, Sordo M, Peniche J and Ostrosky-Wegman P: p53 codon 72 polymorphism, DNA damage and repair, and risk of non-melanoma skin cancer. Mutat Res 619: 38-44, 2007.

35. Kim JW, Roh JW, Park NH, Song YS, Kang SB and Lee HP: Polymorphism of TP53 codon 72 and the risk of cervical cancer among Korean women. Am J Obstet Gynecol 184: 55-58, 2001.

36. Nishikawa A, Fugimoto T, Akutagawa N, Iwasaki M, Takeuchi M, Fujinaga K and Kudo R: p53 polymorphism (codon-72) has no correlation with the development and the clinical features of cervical cancer. Int J Gynecol Cancer 10: 402-407, 2000.

37. Wong YF, Chung TK, Cheung TH, Nobori T, Hamptom GM, Wang VW, Li YF and Chang AM: p53 polymorphism and human papillomavirus infection in Hong Kong women with cervical cancer. Gynecol Obstet Invest 50: 60-63, 200.

38. Bhattacharya $P$, Duttagupta $C$ and Sengupta S: Proline homozygosity in codon 72 of p53: a risk genotype for human papillomavirus-related cervical cancer in Indian women. Cancer Lett 188: 207-211, 2002.

39. Lombard DB, Chua KF, Mostoslavsky R, Franco S, Gostissa M and Alt FW: DNA repair, genome stability, and aging. Cell 120: 497-512, 2005

40 Krtolica A and Campisi J: Cancer and aging: a model for the cancer promoting effects of the aging stroma. Int J Biochem Cell Biol 34: 1401-1414, 2002.

41. Campisi J: Fragile fugue: 553 in aging, cancer and IGF signaling. Nat Med 10: 231-232, 2004

42. Orsted DD, Bojesen SE, Tybjærg-Hansen A and Nordestgaard BG Tumor suppressor p53 Arg72Pro polymorphism and longevity, cancer survival, and risk of cancer in the general population. J Exp Med 204: 1295-1301, 2007.

43. Kawaguchi H, Ohno S, Araki K, Miyazaki M, Saeki H, Watanabe M, Tanaka S and Sugimachi K: p53 polymorphism in human papillomavirus-associated esophageal cancer. Cancer Res 60: 2753-2755, 2000

44. Weihrauch M, Bader M and Lehnert G: Carcinogen-specific mutation pattern in the p53 tumor suppressor gene in UV radiation- induced basal cell carcinoma. Int Arch Occup Environ Health 75: 272-276, 2002.

45. Carr RA, Taibjee DSM and Sanders SA: Basaloid skin tumours: Basal cell carcinoma. Curr Diagnos Pathol 13: 252-272, 2007.

46. Koh D, Wang H, Lee J, Chia KS, Lee HP and Goh CL: Basal cell carcinoma, squamous cell carcinoma and melanoma of the skin: analysis of the Singapore Cancer Registry data 1968-97. Br J Dermatol 148: 1161-1166, 2003.

47. Pfister H: Human papillomavirus and skin cancer. J Natl Cancer Inst Monogr 31: 52-56, 2003

48. Silverberg E, Boring CC and Squires TS: Cancer statistics 1990. CA Cancer J Clin 40: 9-26, 1990.

49. Rosenblatt L and Marks R: Deaths due to squamous cell carcinoma in Australia: is there a case for a public health intervention? Australas J Dermatol 37: 26-29, 1996.

50. Chuang TY, Reizner GT, Elpern DJ, Stone JL and Farmer ER Squamous cell carcinoma in Kauai, Hawaii. Int J Dermatol 34: 393-397, 1995.

51. Raasch B, Maclennan R, Wronski I and Robertson I: Body site specific incidence of basal and squamous cell carcinoma in an exposed population, Townsville, Australia. Mutat Res 422. 101-106, 1998.

52. Brenna SMF, da Silva IDCG, Zeferino LC, Pereira J, Martinez EZ and Syrjänen KJ: Prevalence of codon 72 P53 polymorphism in Brazilian women with cervix cancer. Genet Mol Biol 27 496-499, 2004.

53. Williams JGK, Kubelik AR, Livak KJ, Rafalski JA and Tingey SV: DNA polymorphisms amplified by arbitrary primers are useful as genetic markers. Nucleic Acids Res 18: 6531-6535, 1990.

54. Ribeiro GRH, Francisco G, Teixeira LVS, Romão-Correia RF, Sanches JA Jr, Neto CF and Ruiz IRG: Repetitive DNA alterations in human skin cancers. J Dermatol Sci 36: 79-86, 2004. 